Please do not remove this page

RMIT

UNIVERSITY

\title{
Quantitative evaluation of the adhesion of metallic coatings using cylindrical substrate
}

Elambasseril, Joe; Ibrahim, Raafat

https://researchrepository.rmit.edu.au/esploro/outputs/9921858689101341/filesAndLinks?institution=61RMIT_INST\&index=null

Elambasseril, J., \& Ibrahim, R. (2012). Quantitative evaluation of the adhesion of metallic coatings using cylindrical substrate. Materials and Design, 33(1), 641-651. https://doi.org/10.1016/j.matdes.2011.07.035

Document Version: Accepted Manuscript

Published Version: https://doi.org/10.1016/j.matdes.2011.07.035

Repository homepage: https://researchrepository.rmit.edu.au

(C) 2011 Elsevier Ltd.

Downloaded On 2023/04/27 01:24:21 +1000

Please do not remove this page 
Thank you for downloading this document from the RMIT Research Repository.

The RMIT Research Repository is an open access database showcasing the research outputs of RMIT University researchers.

RMIT Research Repository: http://researchbank.rmit.edu.au/

\section{Citation:}

Elambasseril, J and Ibrahim, R 2012, 'Quantitative evaluation of the adhesion of metallic coatings using cylindrical substrate', Materials \& Design, vol. 33, no. 1, pp. 641-651.

See this record in the RMIT Research Repository at:

http://researchbank.rmit.edu.au/view/rmit:20768

Version: Accepted Manuscript

Copyright Statement: (c) 2011 Elsevier Ltd.

Link to Published Version:

http://dx.doi.org/10.1016/j.matdes.2011.07.035 


\title{
QUANTITATIVE EVALUATION OF THE ADHESION OF METALLIC COATINGS USING CYLINDRICAL SUBSTRATE
}

\author{
J. Elambasseril ${ }^{1}$, R.N. Ibrahim ${ }^{1}$ \\ ${ }^{1}$ Department of Mechanical and Aerospace Engineering, Monash University, Clayton Vic 3800, Australia
}

\begin{abstract}
This paper introduces an effective interfacial fracture toughness test based on interface fracture mechanics theory. This testing method uses a Circumferentially Notched Tensile (CNT) specimen, which is ideally suited for determining the interfacial fracture resistance of coatings. Unlike other interfacial fracture tests, this test is simple to prepare, requires minimum test setup and is easy to model. An interfacial precrack was generated between a nickel coating and mild steel cylindrical substrate to evaluate adhesion strength. In-situ acoustic and SEM analyses were used to determine the crack initiation or the critical load of failure. The critical energy release rate, critical stress intensity factors and phase angle were determined using the $\mathrm{J}$ integral which was determined by applying the critical load to the finite element model. A detailed finite element analysis was carried out to study the effect of different interface precrack positions and mode mixity on energy release rate for different notch angles and elastic modulus ratios. The cracking resistance of the interface was characterised by the notch angle of CNT specimens. The analysis showed an increase in interfacial fracture toughness as phase angle increases and was significant when the phase angle was large. The combined results of computational and experimental analysis showed that any defect or stress concentration at the interface could significantly weaken the adhesion of coating.
\end{abstract}

Keywords: A. Coatings B. Adhesion, C. Finite Element Analysis, D. Circumferential Notch Tensile Test.

*Corresponding author: raafat.ibrahim@monash.edu

$$
0061399051982 \text { (Phone) } 0061399051825 \text { (Fax) }
$$




\section{INTRODUCTION}

It is common in engineering applications for one material to be bound to another, as is the case in adhesive joints, composite materials and thin coatings. Adhesion strength between the coating layer and the substrate is a very significant characteristic of such coatings because various type of loads (i.e. cyclic, thermal and mechanical) are constantly applied to the coated products during actual use[1-2]. It is therefore important, however difficult to test the adhesion of thin coatings[3]. In coatings of many material systems, the weakest element is usually the interface and interfacial delamination is often the major cause of failure [4]. The overall mechanical behaviour of bi-material systems depends on the interfacial features such as discontinuities in elastic and thermal properties, residual stress around the interface and cohesive stress on the interface. During the coating process, interfaces with material properties different from those of the constituent materials, are developed [5]. As a result, the mechanical behaviour and the overall performance of the component are governed by the interface characteristics, rather than by the bulk properties.

The types of specimens used to study interfacial fracture toughness are broadly classified into bimaterial specimens and sandwich specimens. Several methods for testing mechanical properties of a bi-material interface were reviewed by Valli [6], Chalker et al [7], Volinsky et al [8] and Evans and Hutchinson [4]. Bagchi and Evans[9] reviewed the mechanics of thin film decohesion and compared various quantifying methods. However, none of the testing methods was considered to be an ideal method to measure adhesion [10]. Some of the methods based on elastic bending properties of stiff beams for testing interfacial fracture toughness are the three

point bending, four point bending, double cantilever, tapered double cantilever beam, topple beam test, double cleavage drilled compression, Brazil nut and wedge tests. These tests have many advantages[11] such as simple geometry, quantitative analysis using fracture mechanics, the ability to fabricate a large number of samples easily for testing under a variety of conditions. Furthermore an extensive collection of literature exists that can be called on to supply stress/strain solutions for nearly any beam configuration. Nevertheless, these methods have limitations such as time consuming and costly specimen preparation, and for sandwich specimens cannot satisfactorily simulate the stress/strain-loading environment that real 
manufactured parts must endure[12]. In particular, in cases for which the main mode of failure is due to internal stresses, such as those caused by thermal expansion mismatch strains, the delamination process is driven mainly by the elastic energy generated by the stresses. Scratch testing is also commonly used to assess coating adhesion by applying an increasing load on a spherical diamond indenter whilst the coated specimen is moved. The initiation of adhesion failure is normally identified through examination of the surface either by continuously monitoring the frictional force, optical microscopy, or acoustic emission. This method is popular due to the fact that sample preparation is straightforward, applicable for both hard and flexible coatings and the rate of delamination and the locus of failure can be controlled fairly precisely. Conversely, this method has limitations such as poor repeatability, sensitivity to variables that are unrelated to adhesion, complicated analysis and difficulty in obtaining quantitative information about dissimilar systems. Using the existing testing methods as a basis, it is clear that a simple method with the ability to vary the phase angle is needed to evaluate the quantitative interfacial strength of a coated system.

In the present study, a new specimen called Circumferentially Notch Tensile (CNT) test specimen has been established with many advantages over current interfacial fracture toughness specimens. The CNT technique has also been established to be effective for estimating interfacial shear strength and fracture toughness of ceramic coatings [13-14]. As the CNT specimen is cylindrical in nature, it simulates real applications of coatings and hence realistically quantifies the mechanical integrity of coatings. In typical interfacial fracture toughness tests, the direction of crack growth is unpredictable, and a crack often propagates with changing directions, resulting in large data scatter. When a coated CNT specimen is subjected to a tensile load, the $\mathrm{U}$ notch provides a consistent location for the crack to propagate, and the tensile stress ensures that an interfacial crack will advance towards the central axis of the test specimen. Therefore, the CNT methodology reduces the uncertainties of interfacial fracture toughness evaluation. Furthermore, the ability of the CNT technique to confine the plastic deformation within a thin plane allows the interfacial material properties to be investigated under plane strain conditions. In addition, the CNT technique provides a convenient way to investigate mixed mode failure mechanisms by varying the notch angle. 


\section{CIRCUMFERENTIALLY NOTCHED TENSILE (CNT) SPECIMEN}

The Circumferentially Notched Tensile (CNT) specimen was developed to determine the interfacial fracture toughness of coatings by applying pure tensile loads. The specimen is of cylindrical shape and a notch is machined in the middle as shown schematically in Figure 1. CNT specimens are prepared with interfacial precracks for the evaluation of interfacial fracture toughness. By introducing well-defined precracks, the locus of failure in CNT specimens can be easily analysed. The precracked CNT specimen is coated over the notch and subjected to tensile loading for the analysis of cohesive and adhesive fractures. The ends of the CNT specimens are not coated to avoid damaging coatings by the tensile holders.

Finite Element Analysis (FEA) was carried out by modelling the axisymmetric CNT specimen as shown in Figure 2. The notch angle $(\theta)$ of the specimen was varied, to give the crack various orientations with respect to the tensile load (Figure 2). Consequently, the CNT specimens facilitated the study of interfacial fracture toughness over a range of phase angles. The interfacial fracture energy is a function of the phase angle $\Gamma(\psi)$. The crack extends when the energy release rate reaches the fracture energy. For a given configuration of a CNT specimen, the critical force corresponding to crack extension, $F_{c}$, was measured using the in-situ acoustic emission detector. FEA was used to calculate the critical energy release rate, $G_{c}$, i.e., the interfacial fracture toughness $(\Gamma)$ corresponding to the critical force $\mathrm{F}_{\mathrm{c}}$.

\subsection{Interface fracture mechanics approach}

During delamination, stresses near an interface crack tip are always comprised of both mode I and mode II components, thereby leading to a mixed mode fracture. The mode mixity is characterised by a phase angle, $\psi$, which is defined in terms of a complex stress intensity factor, $K=K_{I}+\mathrm{i} K_{I I}$. For a bimaterial interface, the strain energy release rate $(G)$ can be determined by measuring the critical load from the experiment at which the fracture occurs in a specimen for a particular phase angle $(\psi)$. The accuracy of the interfacial failure calculation depends on the stress intensity factors $\left(K_{I}, K_{I I}\right)$, and thus the strain energy release rate. Hutchinson and Suo [15] suggested that if an interface is a low toughness fracture path in joined materials, then mixed mode crack propagation should be considered. This is due to the fact that the crack is not 
developed from the crack tip by mode I loading only, as is in the case of isotropic brittle materials. The mode II component is rather generated from the difference in moduli relating to the interface, which causes asymmetric stress field near the crack tip even though the loading and geometry may be symmetric. Thus the difference in mechanical properties of the coating and substrate causes the distribution of normal and shear stresses at interface [15].

For an interfacial crack between two dissimilar, isotropic materials with Young's modulus $E_{1}$ and $E_{2}$, Poisson's ratios $v_{1}$ and $v_{2}$, and shear modulus $\mu_{1}=E_{1} / 2\left(1+v_{1}\right)$ and $\mu_{2}=E_{2} / 2\left(1+v_{2}\right)$, the interfacial energy release rate was calculated using the $J$ integral and can be written as [16-18]:

$$
J=\frac{1-\beta^{2}}{E^{*}}\left(K_{I}^{2}+K_{I I}^{2}\right)+\frac{1}{2 \mu^{*}} K_{I I I}^{2}
$$

where $\beta, E^{*}$ and $\mu^{*}$ are given as:

$$
\frac{1}{E^{*}}=\frac{1}{2}\left(\frac{1}{E_{1}}+\frac{1}{E_{2}}\right), \quad \frac{1}{\mu^{*}}=\frac{1}{2}\left(\frac{1}{\mu_{1}}+\frac{1}{\mu_{2}}\right) \quad, \quad \beta=\frac{\mu_{1}\left(k_{2}-1\right)-\mu_{2}\left(k_{1}-1\right)}{\mu_{1}\left(k_{2}+1\right)+\mu_{2}\left(k_{1}+1\right)}
$$

and $\kappa=3-4 v$ for plane strain, $\kappa=(3-v) /(1+v)$ for plane stress.

Unlike their analogues in a homogeneous material, $K_{\mathrm{I}}$ and $K_{\mathrm{II}}$ are no longer the pure mode I and II stress intensity factors for an interfacial crack. They are simply the real and imaginary parts of a complex stress intensity factor, whose physical meaning can be understood from the interface traction expressions:

$$
\left(\sigma_{y y}+i \sigma_{x y}\right)_{\theta=0}=\frac{\left(K_{I}+i K_{I I}\right) r^{i \varepsilon}}{\sqrt{2 \pi r}},\left(\sigma_{y z}\right)_{\theta=0}=\frac{K_{I I I}}{\sqrt{2 \pi r}}
$$

where $r$ and $\theta$ are polar coordinates centred at the crack tip. The bi-material constant $\varepsilon$ is defined as:

$$
\varepsilon=\frac{1}{2 \pi} \ln \left(\frac{1-\beta}{1+\beta}\right)
$$


The $J$-integral was calculated using the contour integral evaluation capability of ABAQUS, which is based on the domain integral method. Since the local coordinates of the CNT coincide with the principal stress orientation, under pure tension loading, it was expected that the contribution of $K_{\text {III }}$ to the value of $J$ in this case would be much lower than that of $K_{\mathrm{I}}$ and $K_{\text {II }}$. Thus, along the crack propagation orientation, the contribution of $K_{\text {III }}$ to the $J$ was determined to be negligible for a CNT configuration; and Equation (1) can be rewritten as:

$$
J=\frac{1-\beta^{2}}{E^{*}}\left(K_{I}^{2}+K_{I I}^{2}\right)=\frac{1-\beta^{2}}{E^{*}}\left|K^{*}\right|^{2}
$$

where $K^{*}=K_{\mathrm{I}}+i K_{\mathrm{II}}$, and the magnitude of $K^{*},\left|K^{*}\right|$, can be written as:

$$
\left|K^{*}\right|=\sqrt{\frac{E^{*} J}{\left(1-\beta^{2}\right)}}
$$

It is clear from equation (2) that tension and shear effects are inseparable at the interface and vicinity of the precrack. A measure of the relative portion of shear to normal traction (or mode III) requires the specification of a length quantity $L^{*}$. For oscillatory fields, the phase angle of the mode mixity is uniquely specified by [19]:

$$
\tan \Psi=\left(\frac{\sigma_{y x}}{\sigma_{y y}}\right)_{r=L^{*}}
$$

The length $L^{*}$ is arbitrary, but must be unchanging for a material pair: i.e. $L^{*}$ must be independent of the overall specimen size. For the substrate-film interface of a specimen, the bi-material constant $\varepsilon$ can be estimated. If $\varepsilon$ is small, within the large portion of $K$ dominated region, $\tan \psi=\left(\sigma_{y x} / \sigma_{y y}\right)$ is almost constant [20]. Thus, for a practical purpose, for a small $\varepsilon$, the term of $K^{*} r^{i \varepsilon}$ in equation (2) can be simplified to $K^{*}$, and the associated phase angle of mode mixity can be expressed as:

$$
\tan \Psi=\left(\frac{\sigma_{y x}}{\sigma_{y y}}\right)_{r \longrightarrow 0} \text { or } \quad \tan \Psi=\frac{K_{I I}}{K_{I}}
$$


At the critical condition (onset of the crack growth), $J_{c}$ (critical $J$ integral) can be obtained by applying $\mathrm{F}_{C}$ (critical load obtained experimentally) to the numerical model and subsequently $K_{C}{ }^{*}$ can be evaluated using:

$$
\left|K_{C}^{*}\right|=\sqrt{\frac{E^{*} J_{C}}{\left(1-\beta^{2}\right)}}
$$

However, as $K_{C}{ }^{*}$ is a complex critical stress intensity factor $\left(K_{C}{ }^{*}=K_{I C}+i K_{I I C}\right)$, expressions of $K_{I C}$ and $K_{I I C}$ were determined for CNT specimen using the Finite Element Analysis (FEA) combined with the experimental work.

\section{EXPERIMENTAL DETAILS}

\subsection{Specimen preparation}

The CNT specimens used in the interfacial fracture toughness evaluation were made from cold hardened cylindrical mild steel bars with a diameter of $9.48 \mathrm{~mm}$. Notch angles $(\theta)$ of $0^{0}, 15^{0}, 30^{0}$ and $45^{\circ}$ were machined in the cylindrical specimens as shown in Figure 1 and polished to a finish of 1200 grade (wet and dry) to obtain a smooth surface. A $15 \mu \mathrm{m}$ thick nickel coating was electroplated on the $U$ notched cylindrical substrate over a length of $60 \mathrm{~mm}$ at the middle of the substrate. Prior to the deposition of the nickel coating, a thin layer of $0.85 \pm 0.10 \mu \mathrm{m}$ thick gold was deposited on the notch. The gold was electroplated on the masked substrate to form a precrack of $0.5 \mathrm{~mm}$ wide on the notch surface (Figure 3). This gold coating acted as an interface crack between the nickel coating and the steel substrate. This occurred due to the fact that nickel coatings fail to adhere to gold. The deposition of gold was conducted below 3 amps /2.5V for 3 minutes and the thickness was calculated based on Faraday's law. The mild steel specimens were fully cleaned and deoxidised prior to the deposition of nickel. The nickel plating was performed under $4.0 \mathrm{amps} / 2.4 \mathrm{~V}$ for 8 minutes by using the NiMAC $8170 \mathrm{RW}$ process.

\subsection{Evaluation of critical energy release rate}

The coated CNT specimens with pre-cracks were loaded using an Instron 5500R universal testing machine for uni-axial tensile tests. When failure of the coating occurred, the corresponding applied force was recorded as the critical tensile load. The critical load was 
determined by the detection of elastic waves that generated as a result of the formation and propagation of the interface crack. The generated transient elastic waves were detected using high sensitivity piezoelectric transducers (Model S9204 AD92, Dunegan corp) to provide an early indication of defects or deformation in the material. The acoustic signals were collected using a MISTRAS 2001 Acoustic Emission (AE) system. Intimate mechanical contact was achieved by applying a thin film of grease between the highly sensitive piezoelectric transducer and the specimen and then by tightly securing the transducer using firmly wrapped adhesive tape. The AE system was calibrated at the beginning of each tensile test using a pencil lead break test, to confirm the accuracy of the acoustic source location and the data acquisition system.

The critical load was determined through the comparison of the time of the acoustic events and load displacement curves from the tensile test. The loaded specimens were then cross-sectioned and analysed under optical microscope and Scanning Electron Microscope (SEM) to validate the dominant failure mechanism. SEM analysis was used to distinguish between cohesive failure of the coating and adhesive failure at the interface of the coating-substrate system. The critical energy release rate (interfacial fracture toughness) was determined using the FEA by evaluating the $\mathrm{J}$ integral at the critical load as described below.

\section{EXPERIMENTAL RESULTS}

\subsection{Evaluating interfacial fracture toughness using 0 degree notch angled CNT specimen}

The 0 degree notch angled specimens $(\theta=0)$ were tested using two different crack positions as shown in Figure 2. Two precrack positions at $0.1 \mathrm{~mm}$ and $0.5 \mathrm{~mm}$ from the lower corner of the notch were used in this investigation (as marked by ' $x$ ' in Figure 2).

During the first stage, the coated 0 degree notched CNT specimens were tensile tested using insitu acoustic emission detection with a crack positioned $0.1 \mathrm{~mm}$ from the notch's lower corner. The time, rise time, energy, amplitude, and AE counts were used to identify the crack initiation and its characteristics during the tensile test. The first hit of each loading cycle was considered to be generated at the precrack, assuming that the nickel-gold interface was the weakest link. The later hits were associated with the crack propagation along the interface and deformation of the nickel coating. The results of the AE tests conducted on twelve CNT specimens indicated that 
the proposed testing procedure is repeatable and reliable. AE events were compared with the load displacement curve to determine the critical load (Figure 4). AE events were analysed to find the time of the crack initiation from the pre-crack. This time was used to calculate the critical load from the load-time curve. The average critical load (load at which the interface crack initiates) was determined to be $2412.5 \mathrm{~N}$ and the energy release rate was calculated to be $86 \mathrm{~J} / \mathrm{m}^{2}$ with a standard deviation of 7.8\%. (see Figure 4).

SEM analyses were conducted on tested samples to characterise the coating failure under tensile loading. The SEM analysis confirmed that the crack initiates from the pre-crack and propagates towards the notch's lower corner as shown in Figure 5.

The critical load was used in the finite element model to determine the energy release rate. Finite element analysis was carried out by modelling the axisymmetric CNT specimen (Figure 2). As the properties of electroplated nickel are close to that of bulk Ni below $60{ }^{\circ} \mathrm{C}$ [21] the coating and substrate were modelled using the properties given in Table 1.

The tensile tests of the coating/substrate CNT specimen were modelled using an 8-node biquadratic axisymmetric quadrilateral and reduced integration elements (CAX8R). In order to evaluate the interfacial strength of the coating/substrate interface using FEA, a very fine mesh at the interface was required. This resulted in high computational time due to huge differences in coating and substrate dimensions. This difficulty was efficiently solved using a sub-modelling approach, which included the global and sub-models [22]. The maximum magnitude of normal stress $\left(S_{22}=420 \mathrm{MPa}\right)$ and shear stress $\left(\mathrm{S}_{12}=225 \mathrm{MPa}\right)$ were calculated at the notch corner. The magnitude of the localised stresses at the crack tip reached $150 \mathrm{MPa}$ for the normal stress and 85 MPa for shear stresses. These stresses initiated the crack from the precrack. Each sub-model was compared with the previous sub-model or global model using the overlay method to avoid deviations in results. The element size of the global model was $0.015 \mathrm{~mm}$ and for the final submodel was $0.0025 \mathrm{~mm}$. The nickel coating and steel substrate are assumed to be homogeneous, continuous and isotropic. The precrack was modelled as a seam using an ABAQUS interaction property definition, since the interface crack surfaces in the unloaded state lied next to each other with no gap. The $\boldsymbol{q}$ vector was used to define the direction of crack extension. The $J$-integral and stress intensity factors are path independent, and were evaluated 
using five integral contours. The first contour was provided at the precrack tip, and subsequent contours were generated as contours passing through the adjacent neighbouring elements, moving out from the precrack tip. The values from the last three contours were identical up to five digits and the reported values were consistent from the fifth contour in all cases. The small variations of values between integral contours signify the quality of the mesh for calculating the fracture parameters.

Since the effects of residual stresses and circumferential stresses were very small in the electroplated coatings, they were negligible [23]. From the analyses, it was found that the crack initiated from the precrack and propagated along the interface towards the notch's lower corner. This was confirmed by SEM analysis, which was conducted to study the crack formation along the interface at different stage of loading. No delamination was detected elsewhere between the coating and substrate. At higher tensile loads, cohesive cracks were formed in the coating and tended to spall from the substrate. The spallation of nickel coatings was observed at a much higher load than the delamination load and was approximately equal to $11 \mathrm{kN}$.

In the second stage, 0 degree notched CNT specimens with a pre-crack positioned at $0.5 \mathrm{~mm}$ from the lower corner were analyzed. The AE and SEM studies on six specimens showed that the precrack does not have a large effect on the delamination of the coating. The stresses at the precrack tip were much lower than the stresses at the lower corner of the notch. Therefore it can be concluded that the crack initiated from the lower corner of the notch (Figure 6-a) and propagated along the interface (Figure 6-b). The delamination of coating occurred at the notch's lower corner at a load equal to $5000 \mathrm{~N}$. Upon further loading the nickel coating ruptured at the precrack (Figure 6-c) and at higher tensile loading the coating started to spall from the substrate (Figure 6-d).

CNT Specimens were modelled using finite element analysis with different precrack positions to calculate the stresses at the precrack tip. Finite element results showed that the energy at the precrack tip reduces as the crack moves away from the notch's lower corner. For the crack to be initiated from the crack tip, the precrack should be positioned within $0.2 \mathrm{~mm}$ from the notch's lower corner (Figure 2 with $\mathrm{x}=0.2$ ). Otherwise the delamination will be initiated from the lower corner of the notch. Therefore the precrack positioned at $\mathrm{x}=0.1 \mathrm{~mm}$ in Figure 2 was used to 
determine interfacial fracture toughness using specimens with 15, 30 and 45 degree notch angles as described below.

\subsection{Evaluating interfacial fracture toughness using 15, 30 and 45 degree notch angled specimens}

The coated 15, 30 and 45 degree notched specimens were tensile tested with in-situ acoustic emission detection. The AE events were compared with the corresponding load-time curves to determine the critical load. Out of the six specimens analysed, the average critical load obtained for the 15 degree notch angled specimens was $2800 \mathrm{~N}$ and the energy release rate was calculated to be $260 \mathrm{~J} / \mathrm{m}^{2}$ with a standard deviation of $7.1 \%$. The critical load was confirmed using SEM fractographic analyses that were conducted to study the crack formation along the interface at different stages of loading. For 30 degree notched specimens, the average critical load was determined to be $3450 \mathrm{~N}$ and the calculated energy release rate was $500 \mathrm{~J} / \mathrm{m}^{2}$ with a standard deviation of $5.4 \%$. The Von Mises stress (280 MPa) at the crack tip for 30 degree CNT specimens were higher than the coating's yield at the critical load and the elastic-plastic analysis estimated very small plastic deformation compared with the size of the precrack. The SEM analyses of 15 and 30 notched specimens showed that the delamination initiated from the precrack and propagated along the interface towards the lower corner of the notch. At higher loads the crack widened and when the specimens were loaded above $11 \mathrm{kN}$, spallation of the coating occurred. For the 45 degree notched specimens the SEM analyses showed that the coating initially ruptured at the pre-crack. By analysing six specimens, it was found that the delamination occurred at higher tensile loads. The interfacial fracture toughness was not estimated for 45 degree specimens, as the cohesive fracture occurred in the coating.

Two dimensional axisymmetric finite element models were generated for 15 and 30 degree specimens to analyse the stress distribution and to calculate the fracture parameters. The critical energy release rate, stress intensity factors and phase angle at critical loads for 0, 15 and 30 degree notch angled specimens were calculated using five integral contours and they are given in Table 2. The last two contours gave the same result for the critical energy release rate. As shown in Table 2, as the notch angle increased, the phase angle and critical energy release rate increased. 
In order to compare the interfacial fracture toughness obtained using the CNT method with those obtained using other methods, the phase angle must be considered. Xiao et al [23] investigated the energy dissipated per unit area to create an interfacial fracture by delaminating different thicknesses of electroplated nickel coatings on commercial low carbon steel substrate using a blister test. The interface strength, evaluated by this blister test method for a $15 \mu \mathrm{m}$ Ni coating is 196.86 J/m². Zhang and Xu [24] assessed the interfacial adhesion of electroplated Ni coatings on steel substrate using an extended microbridge technique, and the fracture path of interfacial cracks was examined through cross-sectional high-resolution SEM observation under loading conditions. Their studies indicated that the magnitude of interfacial toughness increased ten to hundred times as the cleaning time of substrate surface was prolonged in a limited duration. Also, in their study, the cross-sectional SEM examination revealed that the weak interface fracture was related to brittle mechanism, whereas the strong interface was a reflection of ductile one. Their study shows the interface toughness increased from $5.28 \mathrm{~J} / \mathrm{m}^{2}$ to $163.6 \mathrm{~J} / \mathrm{m}^{2}$ depending on the cleaning time of substrate surface.

\section{FINITE ELEMENT ANALYSIS OF CNT SPECIMENS}

A thorough elastic and elastic-plastic finite element analysis was carried out to study the initiation and development of the plastic zone in nickel coating/steel substrate systems under tensile loading. The CNT configurations with notch angles ( $\theta$ in Figure 2) of 0, 15, 30, 45 and 60 degrees were considered in these analyses. The J-integral was calculated for different configurations and compared with the previously obtained critical energy release rate for the bimaterial system under consideration to predict its fracture. The coating and substrate were modelled using the elastic-plastic properties listed in Table 1.

Plasticity effects were considered for the nickel coating and the steel substrate at the critical load and were assumed to be governed by Von Mises-yield criteria, and isotropic hardening based on the stress-plastic strain curve. The plastic deformation was taken into consideration in estimating the strain energy of the debonding due to the ductile nature of coating. The deformation theory Ramberg-Osgood plasticity model was used to define the behaviour of ductile coating under static loading. The Ramberg-Osgood model is expressed as 


$$
E \varepsilon=\sigma+\alpha\left(\frac{|\sigma|}{\sigma^{0}}\right)^{n-1} \sigma
$$

This equation expresses the true strain $(\varepsilon)$ as a function of the true stress $(\sigma)$, where $E$ is Young's modulus, $\sigma$ is the stress, $\varepsilon$ is the strain, $\alpha$ is the yield offset, $\sigma^{0}$ is the yield stress, such that when $\sigma=\sigma^{0}, \varepsilon=(1+\alpha) \sigma^{0} / E$ and $n$ is the hardening exponent for the plastic (nonlinear) term.

Figures 7 to 10 show the Von Mises stress and plastic strain distributions at the crack tip at critical loads. To be considered for linear elastic analysis, the maximum stress at the interface crack tip should be less than the yield stress of both materials when the delamination occurs [12]. However, the Von Mises stress (280 MPa) at the crack tip for 30 degree CNT specimens was higher than the coating's yield strength at critical load. Furthermore, the elastic-plastic analysis estimated very small plastic deformation compared with the size of the precrack. The CNT specimens with notch angles greater than 15 have plastic deformation at the crack tip resulting from the large shear stress. Therefore the use of linear elastic fracture mechanics for CNT specimens with notch angles up to 15 degree are satisfied and can simulate the brittle fracture of coated system even when the ductile coating and substrate are used. In CNT specimens, the reduced section deforms in-elastically while the ends of the specimens were still loaded elastically. Since the amount of elastic contraction (Poisson's ratio) is small compared to the inelastic contraction of the reduced section, a restriction of plastic flow was developed. This restriction was in the nature of a reaction-stress system, such that the $\sigma_{\mathrm{xx}}$ and $\sigma_{\mathrm{zz}}$ constrain the flow in $\sigma_{y y}$ (load direction). Thus the uniaxial stress state of the smooth bar was changed to a triaxial stress system in a circumferentially notched bar. Furthermore, the fully circumferential crack did not have an end in a plane stress region and thus plane strain conditions are possible notwithstanding the small size of specimen [25].

\subsection{Elastic-Plastic Stress analyses for different precrack position with respect to the notch lower corner}

In this section, the effect of precrack position on stress and strain distributions using different notch angled CNT specimens is discussed. The notch angles ( $\theta$ in Figure 2$)$ considered in this investigation were $0,15,30,45$ and 60 degrees. Various crack positions investigated were at 
distances of $0.01,0.1,0.2,0.3,0.4$ and $0.5 \mathrm{~mm}$ (x in Figure 2) from the lower corner of the notch. The specimens were modelled using a load of $3750 \mathrm{~N}$ and a precrack width of $0.5 \mathrm{~mm}$. The crack surface displacement and J-integral methods were used to predict crack propagation along the interface. It was found that the energy release rate at the precrack tip decreased as the precrack moved away from the notch corner. The comparison of the energy release rate obtained for different precrack positions with respect to the notch corner is shown in Figure 11. It was found that, for the crack to be initiated from the precrack tip, the precrack should be positioned within $0.2 \mathrm{~mm}$ from the notch's lower corner (Figure 2 with $\mathrm{x}=0.2$ ). Otherwise the delamination would initiate from the lower corner of the notch.

\subsection{The effect of notch angle on energy release rate and Mode mixity}

The mode mixity or phase angle was estimated at different crack positions for different notch angles using finite element as shown in Figure 12. The J-integrals for 0,15 and 30 degree notch angled specimens were obtained using finite element elastic analysis. The 45 and 60 degree specimens were not included in the analyses due to the significant amount of plastic deformation at the precrack tip resulting from the large shear stress. The maximum stress in the coatingsubstrate system was much less than the yield stress of both materials when the delamination occurred for specimens having notch angles upto 15 degrees. The stress at the crack tip for 30 degree CNT specimens was slightly higher than the coating's yield strength at critical load. So the elastic analyses were considered for ductile coatings on CNT specimens having a notch angle upto $30^{\circ}$.

\subsection{Effect of stiffness ratio of coatings and substrates on the energy release rate}

The CNT specimens were also analysed using finite element to investigate the effect of the stiffness ratio on the energy release rate and phase angle. E1/ E2 denote the ratio of Young's modulus of the coating material to the Young's modulus of the substrate. The Poisson's ratio was taken as 0.3 . We observed that the energy release rate decreased, as the stiffness ratio of coatings to substrates decreased for a given notch angle (Figure 13).

The change of energy release rate with phase angle and stiffness ratio for three different notch angles is shown in Figure 14. 


\section{CONCLUSIONS}

A new method of measuring the adhesion strength of coatings to their substrate has been demonstrated. This paper detailed the test approach of evaluating interfacial fracture toughness of coatings using a circumferentially notched tensile test specimen. Five notch angles were analysed. The method employed in this study is practical and can be used to determine critical interface fracture properties of bimaterials. The results showed an increase in the interfacial fracture toughness with an increase in phase angle. This is due to the increase in shear stress as the notch angle increases. At critical load, cracks initiated from the precrack and propagated towards the lower notch corner for a pre-crack positioned at $0.1 \mathrm{~mm}$ from the notch's lower corner for 0, 15 and 30 degree notch angled specimens. For a 45 degree notched specimen, the coating initially ruptured at the precrack and then delaminated. For a pre-crack positioned at 0.5 mm from the notch's lower corner, the crack did not initiate at the precrack. The coating separated from the notch's lower corner and propagated along the interface. The stresses developed at the precrack tip were much lower compared to the stress at the lower corner of the notch. The delamination at the notch corner occurred at a load of approximately $5000 \mathrm{~N}$ in the case of a $0^{0} \mathrm{CNT}$ and at $6200 \mathrm{~N}$ for a $15^{\circ} \mathrm{CNT}$ specimen.

This study has shown that the stress concentration at the lower corner of the notch is sufficient to initiate the interface crack. Therefore, CNT specimens without precrack may be used to investigate the interfacial fracture toughness of coated materials.

\section{REFERENCES}

1. Richard, P., et al., Combination of scratch-test and acoustic microscopy imaging for the study of coating adhesion. Surface and Coatings Technology, 1997. 91(1-2): p. 83-90.

2. Oskouei, R.H. and R.N. Ibrahim, Restoring the tensile properties of PVD-TiN coated Al 7075-T6 using a post heat treatment. Surface and Coatings Technology, 2011. 205(15): p. 3967-3973.

3. Ollendorf, H. and D. Schneider, A comparative study of adhesion test methods for hard coatings. Surface and Coatings Technology, 1999. 113(1-2): p. 86-102.

4. Evans, A.G. and J.W. Hutchinson, The thermomechanical integrity of thin films and multilayers. Acta Metallurgica et Materialia, 1995. 43(7): p. 2507-2530.

5. Mukherjee, S., C.R. Ananth, and N. Chandra, Effects of interface chemistry on the fracture properties of titanium matrix composites. Composites Part A: Applied Science and Manufacturing, 1998. 29(9-10): p. 1213-1219.

6. Valli, J., A review of adhesion test methods for thin hard coatings. 1986, AVS. p. 30073014. 
7. Chalker, P.R., S.J. Bull, and D.S. Rickerby, A review of the methods for the evaluation of coating-substrate adhesion. Materials Science and Engineering A, 1991. 140: p. 583-592.

8. Volinsky, A.A., N.R. Moody, and W.W. Gerberich, Interfacial toughness measurements for thin films on substrates. Acta Materialia, 2002. 50(3): p. 441-466.

9. Bagchi, A. and A.G. Evans, The mechanics and physics of thin film decohesion and its measurement. Interface Science, 1996. 3(3): p. 169-193.

10. Mittal, K.L., Adhesion Measurement of Films and Coatings. 1995, Tokoyo: VSP.

11. Taylor and F. Group, Adhesion Measurement Methods: Theory and Practice 2006, LLC, Broken Sound Parkway, Boca Raton, Florida: CRC Press. 436.

12. Volinsky, A.A., N.R. Moody, and W.W. Gerberich, Interfacial toughness measurements for thin films on substrates. 2002. 50(3): p. 441-466.

13. Elambasseril, J., R.N. Ibrahim, and R. Das, Evaluation of fracture characteristics of ceramic coatings on stainless steel substrates using circumferentially notched tensile specimens. Composites Part B: Engineering. In Press, Accepted Manuscript.

14. Elambasseril, J., R.N. Ibrahim, and R. Das, Determination of Mechanical Properties of TiN Coating Using a Notched Cylindrical Stainless Steel Substrate. Materials Science Forum, Trans Tech Publications, Switzerland, 2010. 654-656: p. 1860-1863.

15. Hutchinson, J.W., Suo, Z, Mixed Mode Cracking in Layered Materials Advances in Applied Mechanics, 1992. 29: p. 63-191.

16. Suo, Z. and J.W. Hutchinson, Interface crack between two elastic layers. International Journal of Fracture, 1990. 43(1): p. 1-18.

17. Shih, C.F. and R.J. Asaro, Elastic-plastic and asymptotic fields of interface cracks. International Journal of Fracture, 1990. 42(2): p. 101-116.

18. Suo, Z. and J.W. Hutchinson, Sandwich test specimens for measuring interface crack toughness. Materials Science and Engineering: A, 1989. 107: p. 135-143.

19. Shih, C.F., Cracks on bimaterial interfaces: elasticity and plasticity aspects. Mat. Sci. Eng A-Struct, 1991. 143(1-2): p. 77-90.

20. Rice, J.R.J.R., Elastic Fracture Mechanics Concepts For Interfacial Cracks. Journal of applied mechanics, 1988. 55(1): p. 98-103.

21. Luo, J.K., et al., Young's modulus of electroplated Ni thin film for MEMS applications. Materials Letters, 2004. 58(17-18): p. 2306-2309.

22. Bogdanovich, A.E. and I. Kizhakkethara, Three-dimensional finite element analysis of double-lap composite adhesive bonded joint using submodeling approach. Composites Part B:Engineering, 1999. 30(6): p. 537-551.

23. Xiao, L.H., et al., A novel blister test to evaluate the interface strength between nickel coating and low carbon steel substrate. Materials Science and Engineering: A, 2009. 501(1-2): p. 235-241.

24. Zhang, $\mathrm{X}$. and $\mathrm{K} . \mathrm{Xu}$, On the evaluation of the adhesion of electroplated Ni coatings upon steel substrate with extended microbridge technique. Materials Science and Engineering: A, 2008. 494(1-2): p. 122-126.

25. Ibrahim, R.N. and H.L. Stark, Validity requirements for fracture toughness measurements obtained from small circumferentially notched cylindrical specimens. Engineering Fracture Mechanics, 1987. 28(4): p. 455-460. 


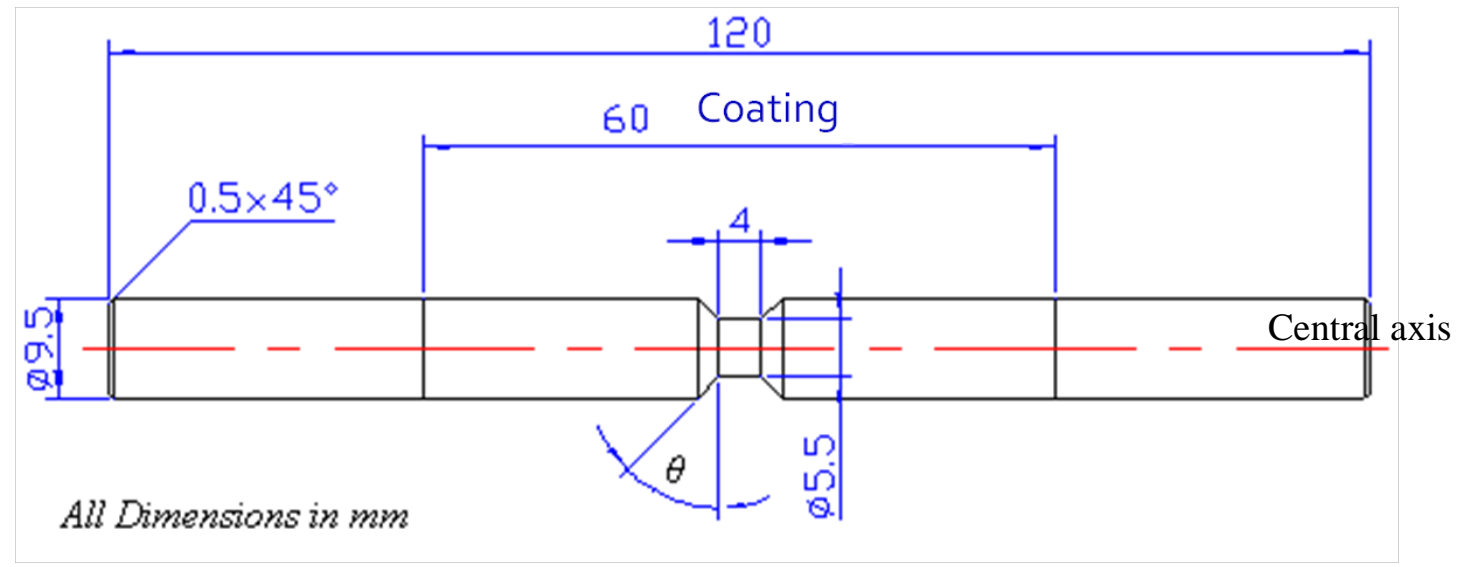

Figure 1: A typical CNT specimen with a U notch of angle $\theta$, where $\theta$ can be varied to assess the effect of the phase angle on interfacial fracture toughness 


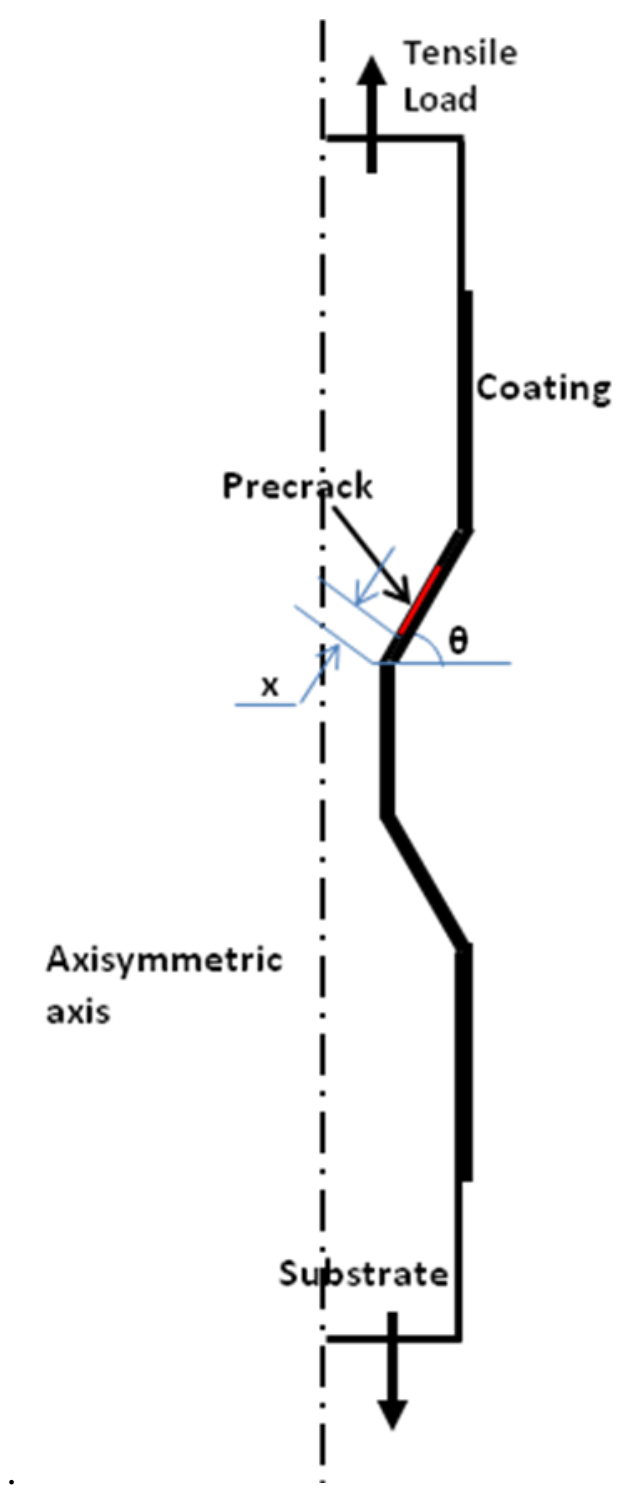

Figure 2: Showing precrack positions used in this investigation, where $\mathrm{x}$ is the distance of the pre-crack from the lower notch corner. 


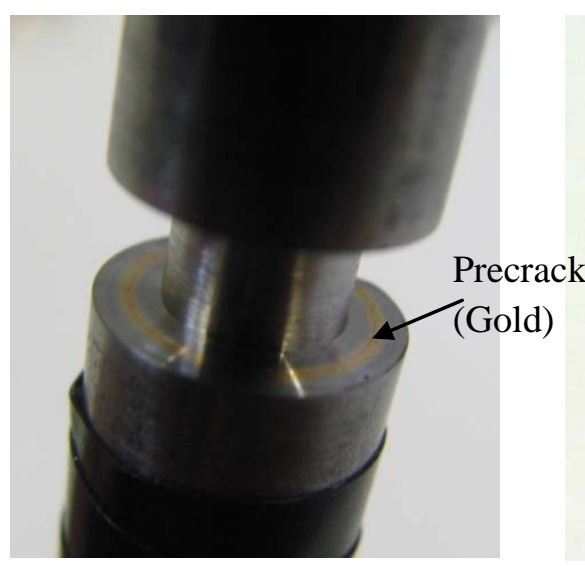

(a)

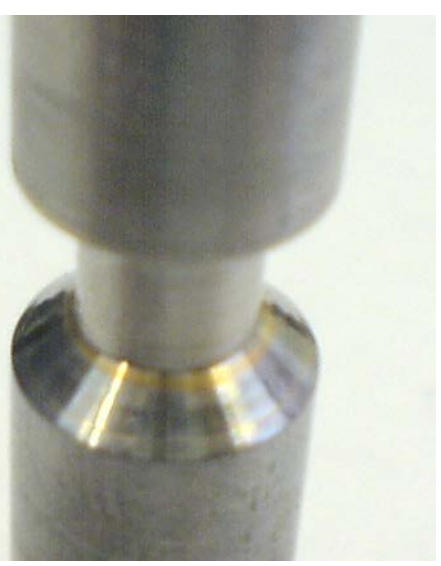

(b)

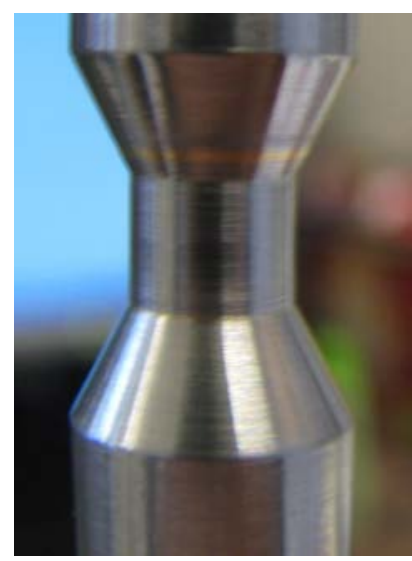

(c)

Figure 3: Gold deposited as a precrack on the CNT specimen where (a) $\theta=0$ degree (b) $\theta=30$ degree and (c) $\theta=45$ degree. 


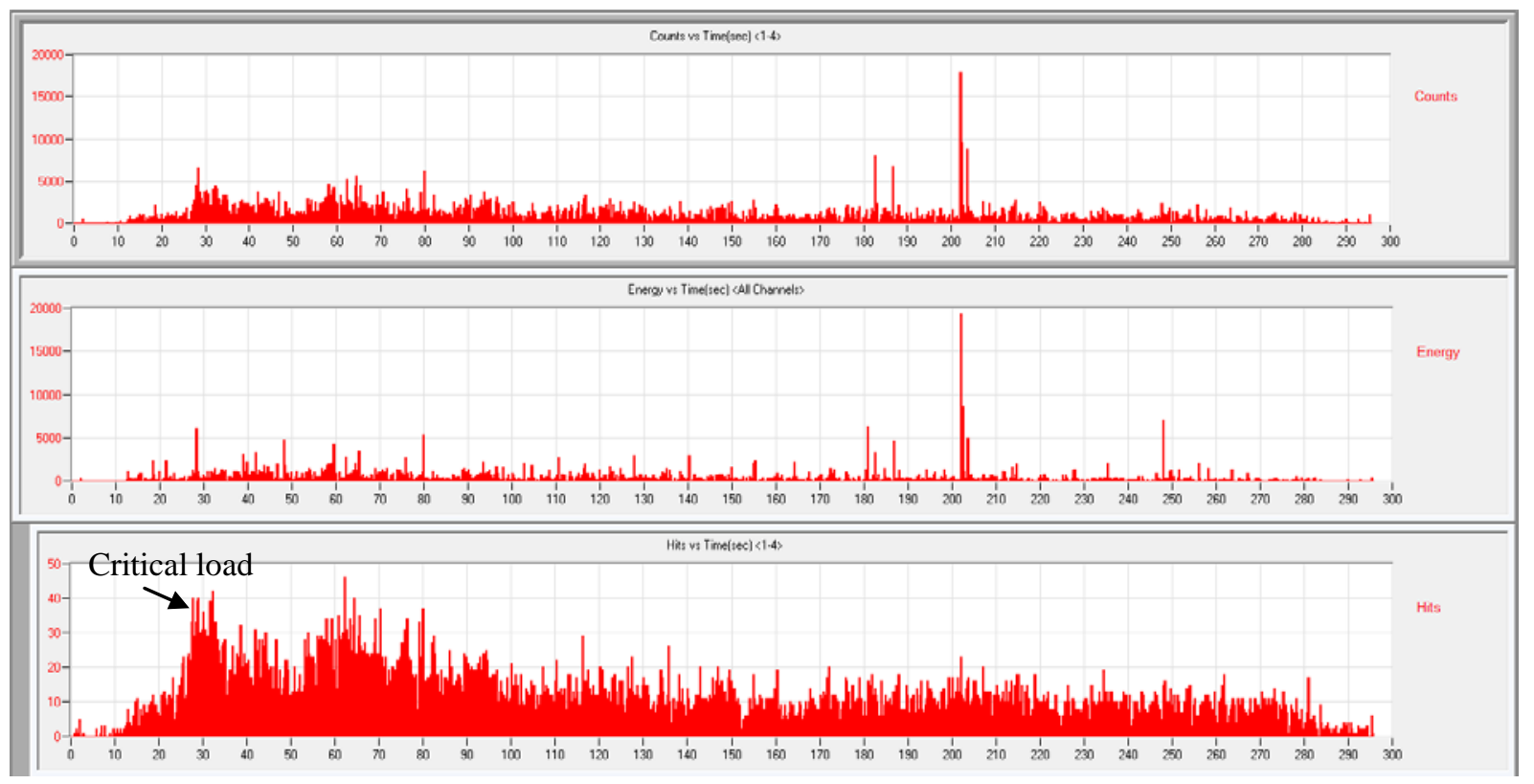

(a)

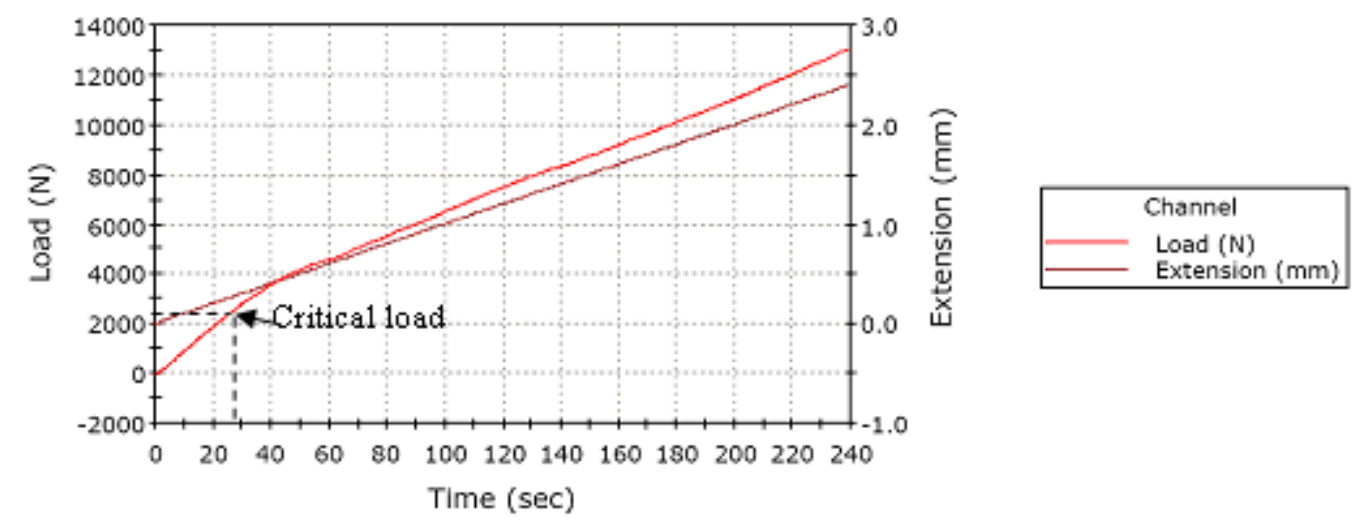

(b)

Figure 4: (a) Acoustic emission events from $0^{0}$ notch angled CNT specimen with a precrack positioned at $0.1 \mathrm{~mm}$ from the notch's lower corner under tensile load and the hit at the critical load is marked (b) the corresponding load displacement curve showing the critical load. 

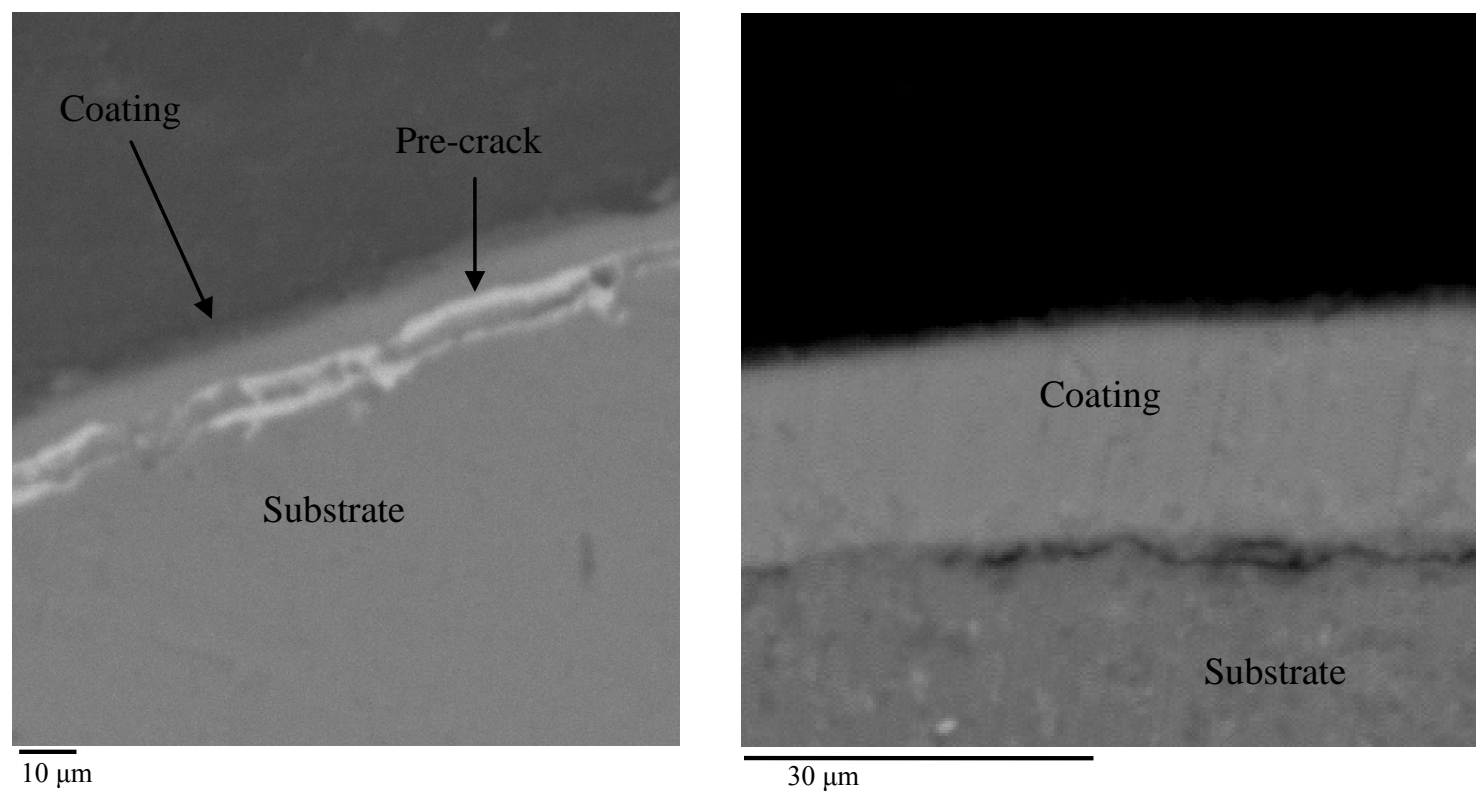

Figure 5: Fractographic analysis of a cross sectioned CNT specimen for a crack positioned at $0.1 \mathrm{~mm}$ from the lower corner of the notch ( $\mathrm{x}=0.1$ as indicated in Figure2). Delamination began at the pre-crack and propagated along the interface towards the lower corner of the notch. 


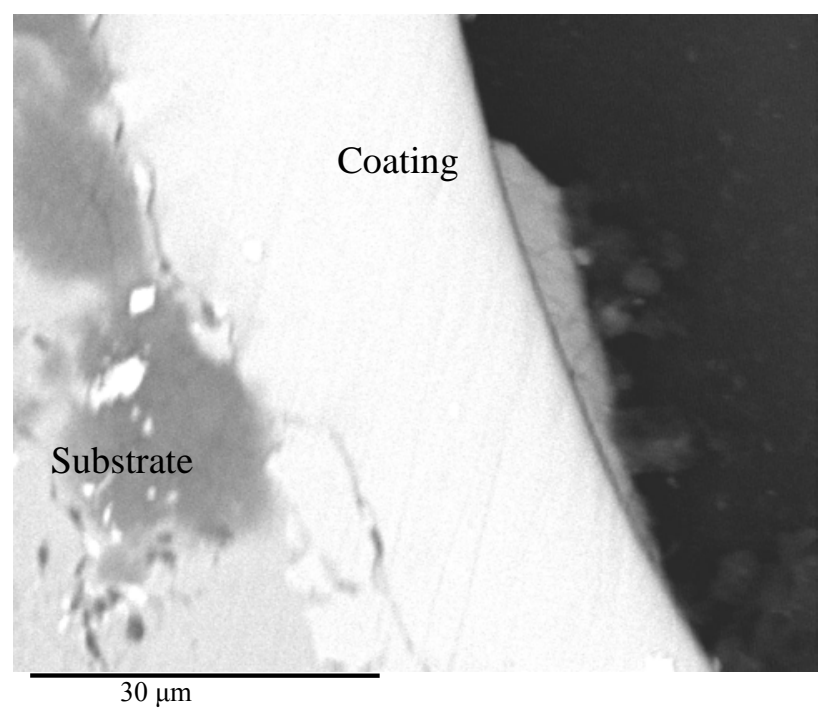

(a)

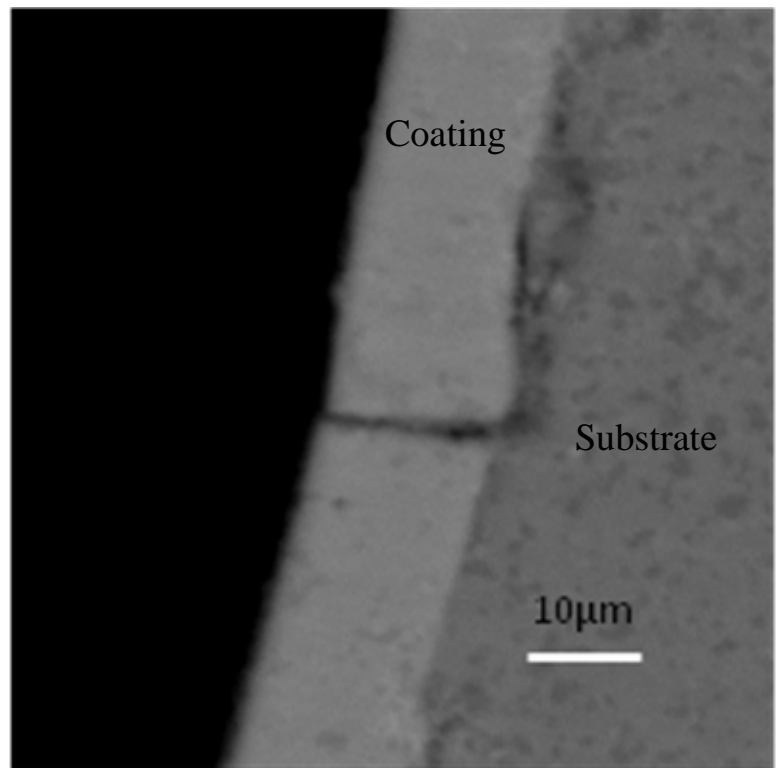

(c)

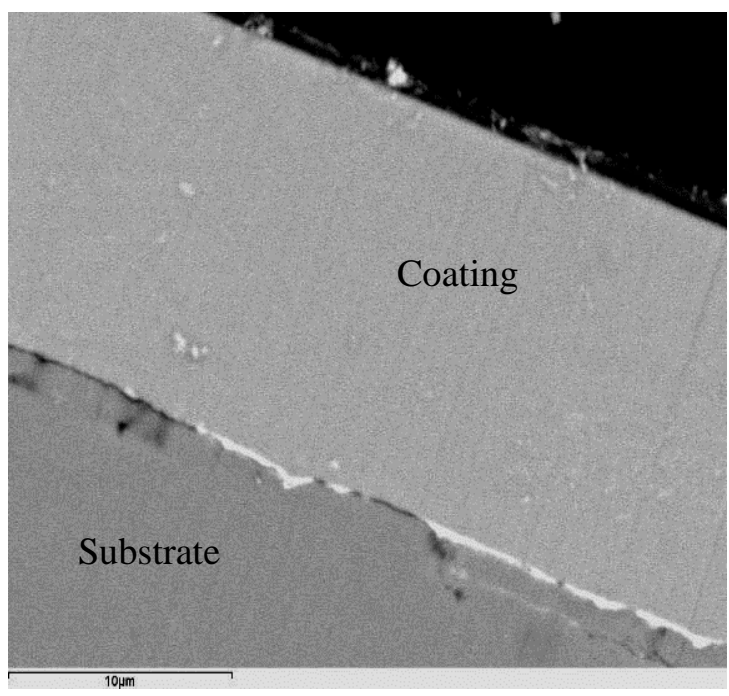

(b)

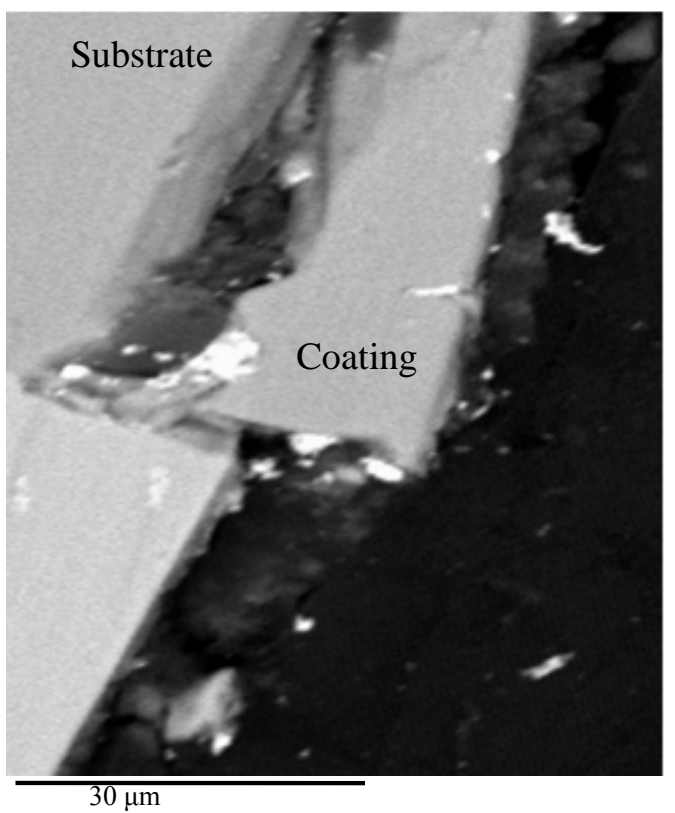

(d)

Figure 6: Fractographic analysis of a cross sectioned CNT specimen for a crack positioned at $0.5 \mathrm{~mm}$ from the lower corner of the notch. (a) Showing the delamination of the coating started from the lower corner of the notch (b) Showing the crack propagation along the interface (c) showing the cohesive failure of the coating (d) and showing the spallation of coating from the substrate. 


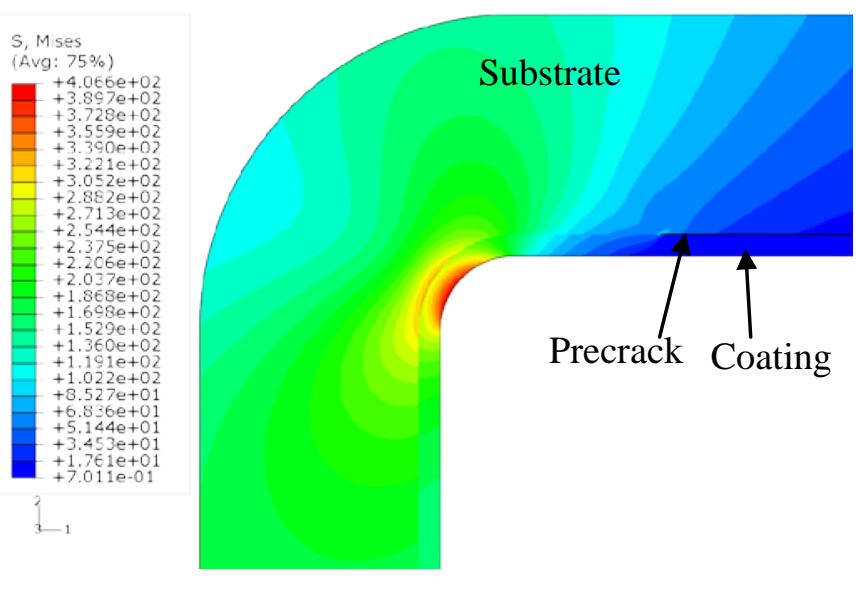

(a)

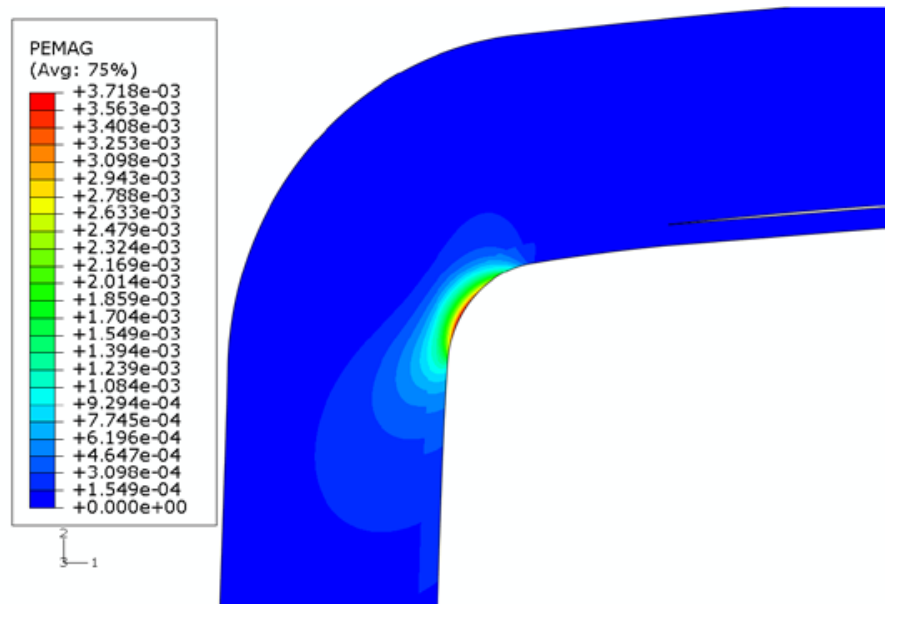

(b)

Figure 7: Contour plots of $0^{0}$ angle CNT specimens at the critical load - a) sub model showing Von Mises stress distribution b) plastic strain for a crack positioned at $0.1 \mathrm{~mm}$ from the lower corner of the notch.

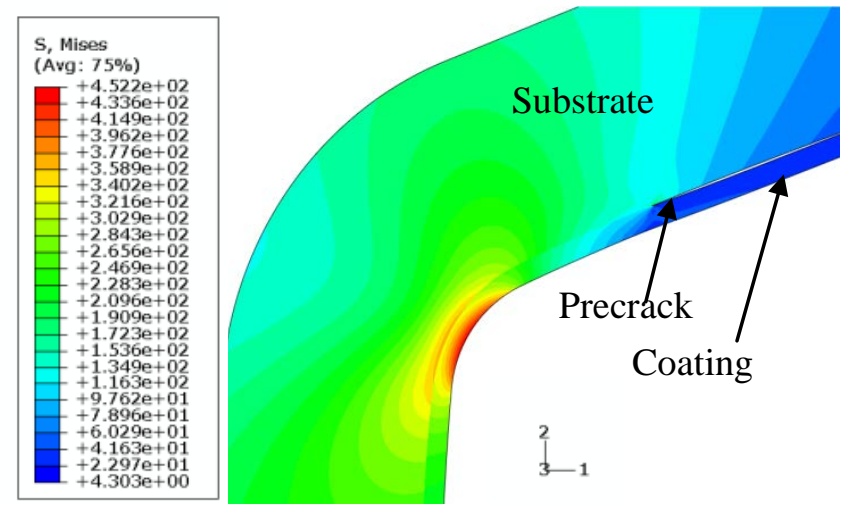

(a)

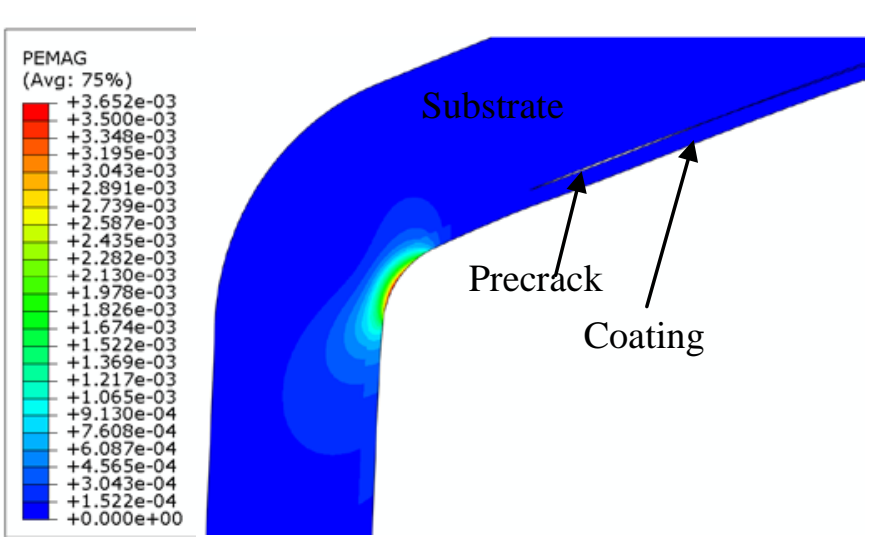

(b)

Figure 8: Contour plots of $15^{0}$ angle CNT specimens at the critical load - a) sub model showing Von Mises stress distribution b) plastic strain for a crack positioned at $0.1 \mathrm{~mm}$ from the lower corner of the notch. 


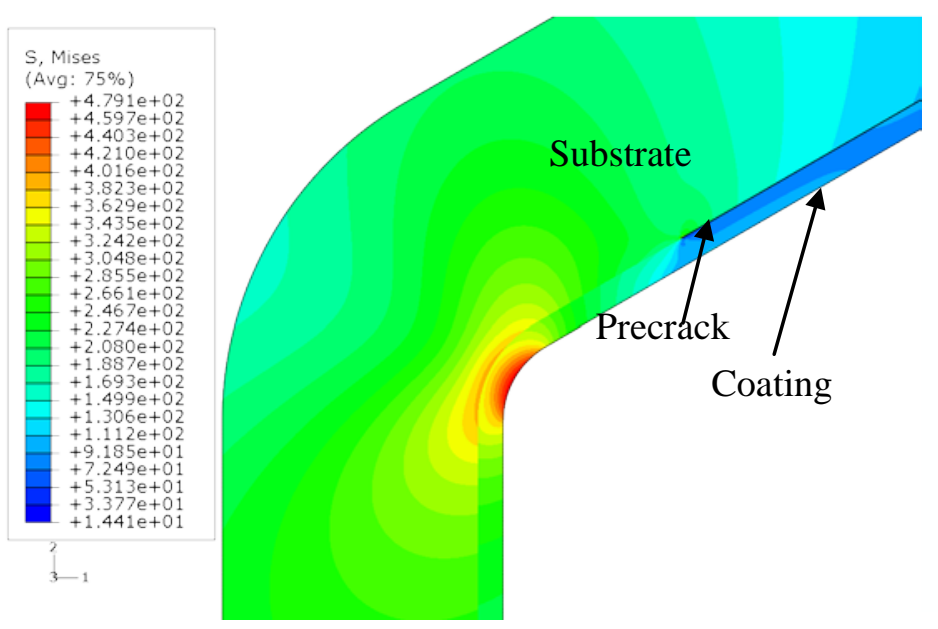

(a)

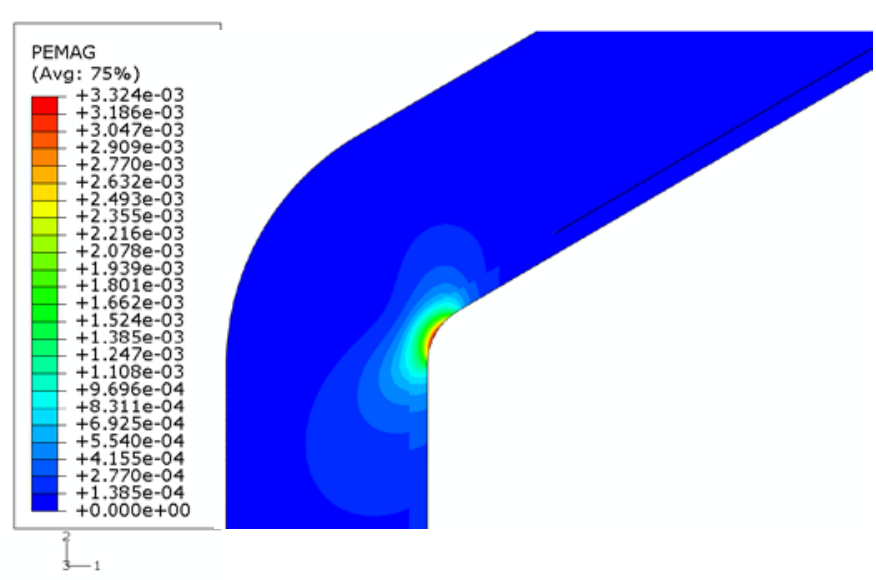

(b)

Figure 9: Contour plots of $30^{\circ}$ angle CNT specimens at the critical load - a) sub model showing Von Mises stress distribution b) plastic strain for a crack positioned at $0.1 \mathrm{~mm}$ from the lower corner of the notch.

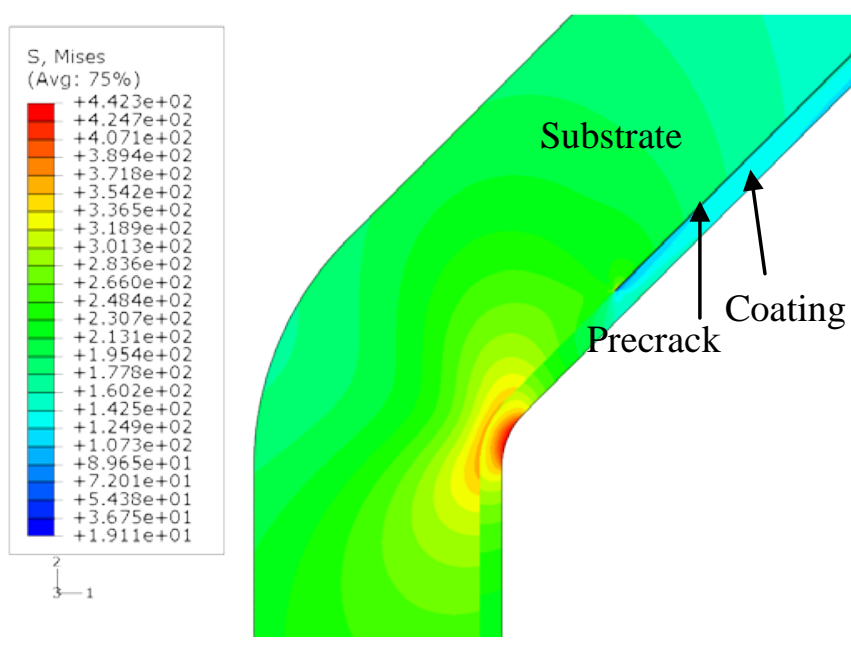

(a)

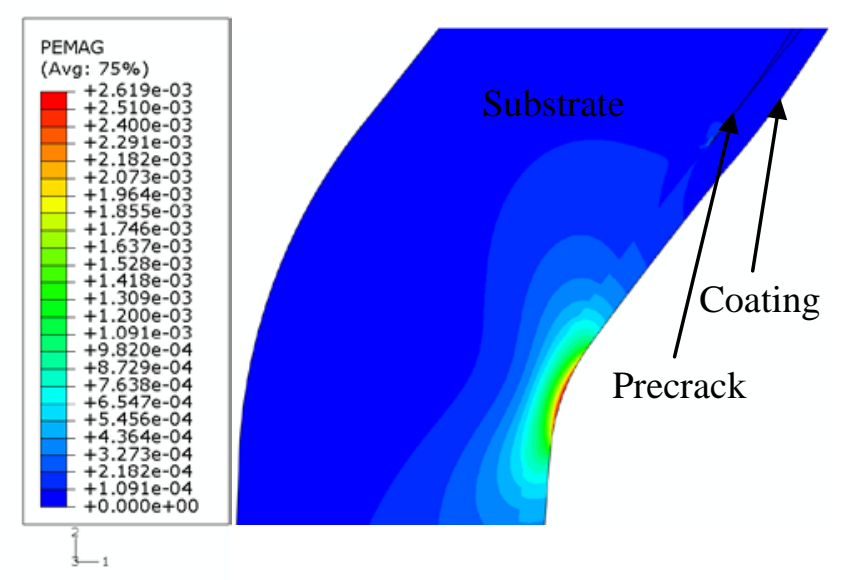

(b)

Figure 10: Contour plots of $45^{\circ}$ angle CNT specimens at the critical load - a) sub model showing Von Mises stress distribution b) Plastic strain for a crack positioned at $0.1 \mathrm{~mm}$ from the lower corner of the notch. 


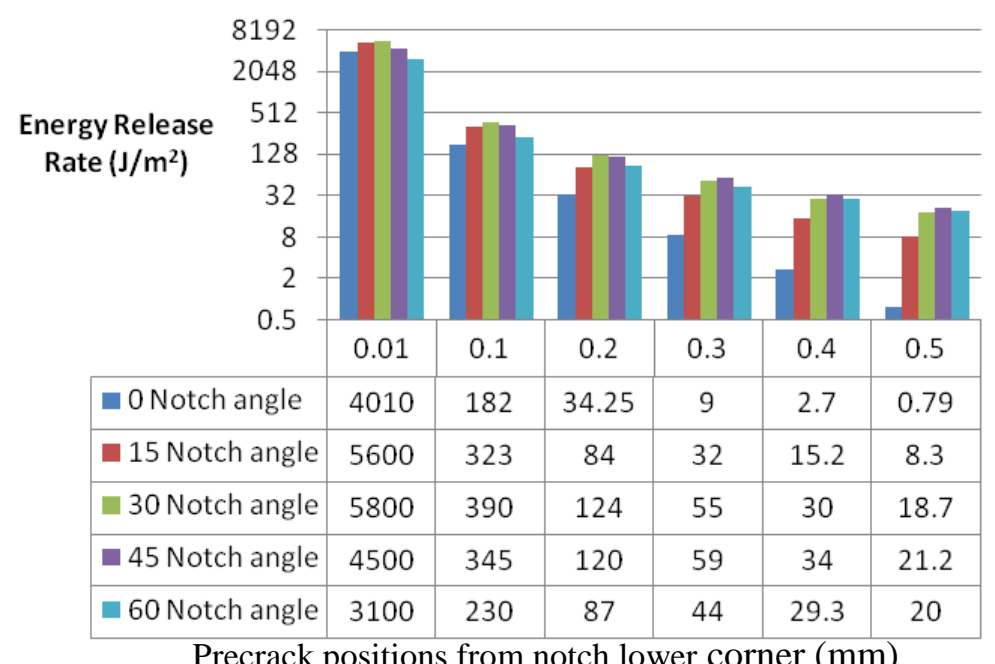

Figure 11: Effect of crack positions on the energy release rate calculated using an assumed load of $3750 \mathrm{~N}$ (log scale is used for the energy release rate with the actual values given above in the table)

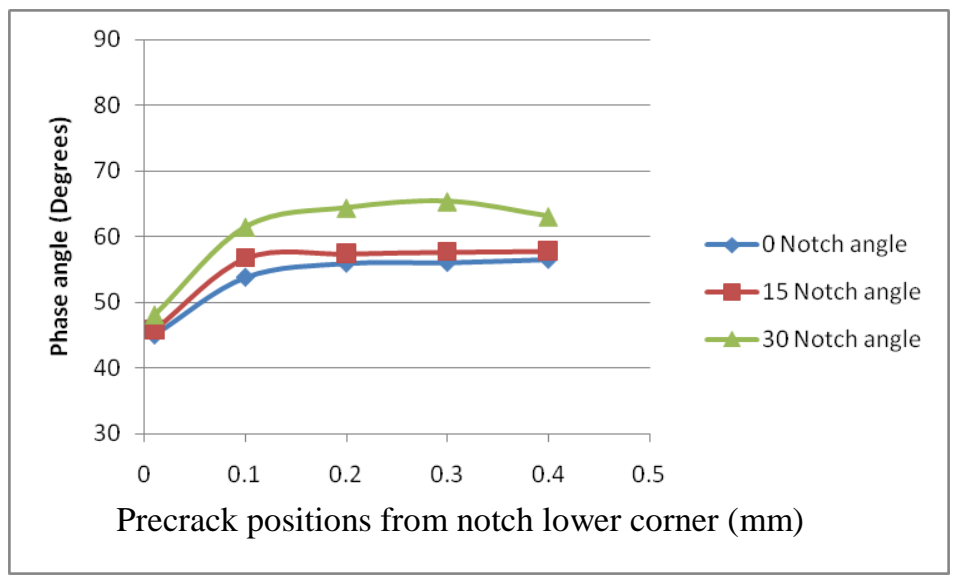

Figure 12: Phase angles calculated for 0, 15 and 30 degree notch angled CNT specimens 


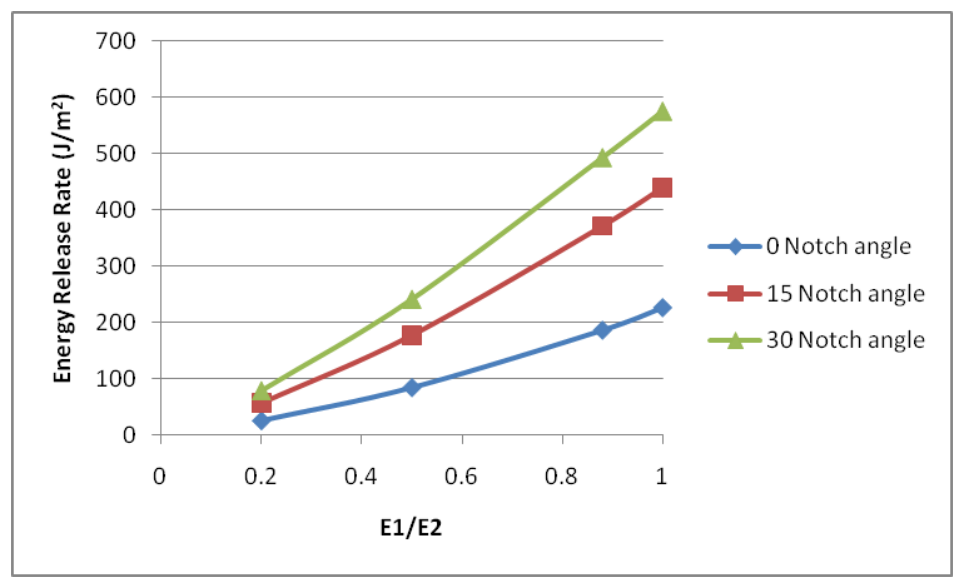

Figure 13: Variation of energy release rate with the ratio of Young's modulus of the coating material to the Young's modulus of the substrate.

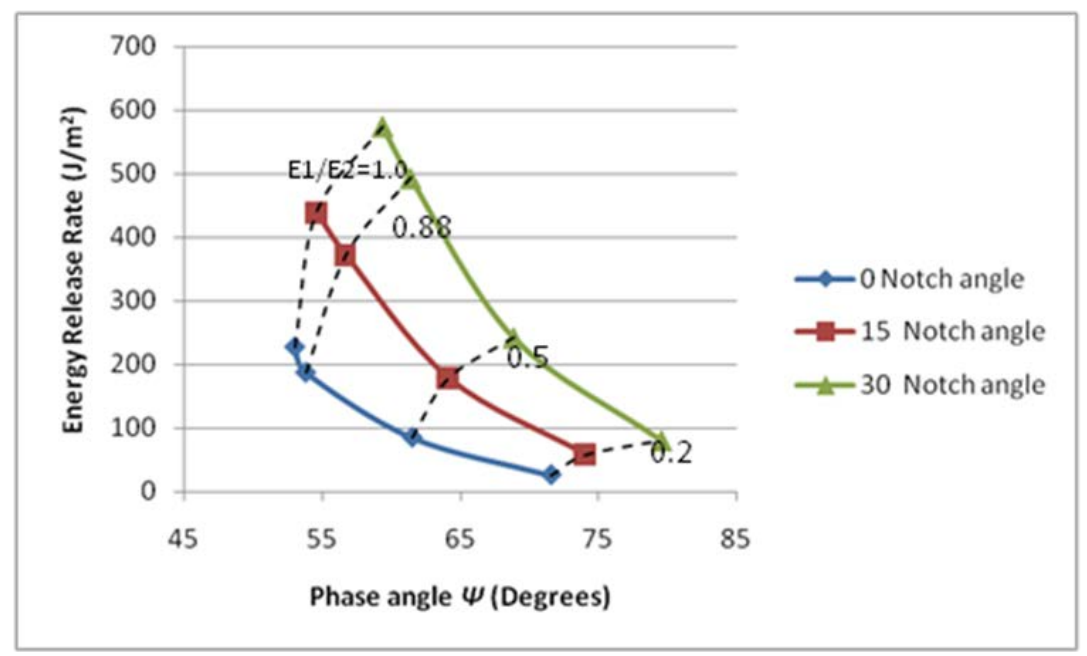

Figure 14: Energy release rate with phase angle for different ratios of modulus. Dotted lines show the different ratio of modulus. 
Table 1: Typical material properties used in FEM analysis

\begin{tabular}{|l|l|l|l|l|l|}
\hline & $\begin{array}{l}\text { Young's } \\
\text { Modulus } \\
\text { MPa }\end{array}$ & $\begin{array}{l}\text { Poisson } \\
\text { ratio v }\end{array}$ & $\begin{array}{l}\text { Yield stress } \\
\text { MPa }\end{array}$ & Exponent & $\begin{array}{l}\text { Yield } \\
\text { offset }\end{array}$ \\
\hline Substrate & 210000 & 0.29 & 300 & 5 & 0.2 \\
\hline Coating & 185000 & 0.3 & 240 & 3.8 & 0.2 \\
\hline
\end{tabular}

Table 2: Fracture parameters obtained by applying the critical load to the FE model

\begin{tabular}{|c|c|c|c|c|c|c|c|}
\hline $\begin{array}{c}\text { Notch } \\
\text { angle* } \\
\text { (Degree) }\end{array}$ & $\begin{array}{l}\text { Number } \\
\text { of tests }\end{array}$ & $\begin{array}{c}\text { Average } \\
\text { critical } \\
\text { load } \\
\text { (N) }\end{array}$ & $\begin{array}{c}\text { Average } \\
\text { energy } \\
\text { release rate } \\
\left(\mathrm{J} / \mathrm{m}^{2}\right)\end{array}$ & $\begin{array}{c}\text { Standard } \\
\text { deviation } \\
(\%)\end{array}$ & $\mathbf{K}_{\text {II }}$ & $\mathbf{K}_{1}$ & $\begin{array}{c}\text { Phase } \\
\text { angle } \\
\text { (Degrees) }\end{array}$ \\
\hline 0 & 12 & 2412.5 & 86 & 7.8 & 3.1 & 2.56 & 50.45 \\
\hline 15 & 6 & 2800 & 260 & 7.1 & 6.3 & 4.2 & 56.3 \\
\hline 30 & 6 & 3450 & $500^{\#}$ & 5.4 & 9.1 & 5 & 61.2 \\
\hline
\end{tabular}

*Refer figure 2

\# Von Mises stress at crack tip is higher than coating's yield stress 